\title{
Low-temperature calcite precipitation in sand using CIPS
}

Anders Palmén MSC

Geotechnical Engineer, PEAB Civil Engineering, Stockholm, Sweden

Graham Price $\mathrm{PhD}$

Geologist/Owner, Lithic Australia Pty Ltd, Melbourne, Australia
Morgan Axelsson LicEng

Geotechnical Specialist, Swedish Transport Administration, Stockholm, Sweden

Stefan Larsson PhD

Professor, KTH Royal Institute of Technology, Stockholm, Sweden

The permeation grouting system CIPS (calcite in situ precipitation system) stabilises granular soil by hydrolysing the urea and causing calcite crystals to precipitate at the contact points of the grains. At low temperatures, the activity of urea hydrolysis is slow, causing concern that the CIPS system might not build sufficient strength in order to be an efficient soil stabilisation method. Most of the documented experience and research have been conducted in Australia; in order to examine the suitability of CIPS under Scandinavian climate conditions, where the operating temperature for the method needs to be adjusted to around $10^{\circ} \mathrm{C}$, a laboratory study was conducted. The test cores were all treated and stabilised in a temperature-controlled room simulating Scandinavian ground conditions. After different lengths of curing time, some of the cemented samples were tested saturated for unconfined compressive strength (UCS); the other samples were allowed to dry at either 10 or $20^{\circ} \mathrm{C}$ before they were tested for UCS. The tests showed a rather obvious increase in strength especially after allowing the spent fluid to deplete, causing the samples to dry out; only a slight difference in UCS increase was recorded between the drying temperature of 10 and $20^{\circ} \mathrm{C}$.

\section{Introduction}

The calcite in situ precipitation system (CIPS) is a twocomponent permeation grouting system in which the two water-based liquids are composed of calcium chloride, urea, tetra sodium, sodium carbonate, sodium sulfite and the enzyme urease. The chemical reaction, outlined in Figure 1, imitates one of the natural processes for formation of sandstone through precipitation of calcite crystals as a coating around the soil grains (Ismail et al., 2000, 2002; Kucharski et al., 2000; Price, 1988a), thus creating bonds at the particleto-particle contact points (Figure 2) and increasing the strength of the soil matrix (Ismail et al., 2000; Price, 1988b). Just as repeated treatments result in higher unconfined compressive strength (UCS), the strength increase is also highly dependent on the individual grain strength, density, decreasing particle size of host grains, and the roundness and nonangularity of soil grains (Ismail et al., 2002; Tatzki, 2003).

A few building projects have been conducted in Australia by Lithic Australia Pty Ltd and Earth Bond Solutions Pty Ltd, as well as an experimental treatment of an old track-bed within the London Underground (Vaughan et al., 2001). If permeation grouting systems, such as CIPS, can be developed to reach their full potentials, large benefits can be achieved from their constructional applications - financially and environmentally. An extensive potential area of application is erosion control of road and railroad embankments. Other potential areas of application are soil liquefaction, desertification, coastal erosion, slope stability, underpinning of constructions and restoration of heritage-listed buildings.

Temperature is one of the factors governing the size and numbers of calcite crystals formed through precipitation that later govern the efficiency of the strength increase. The activity of the urease is dependent on the temperature of the fluid: a higher temperature results in higher urease activity, leading to less urease usage for the accurate reaction rate. If the urease activity is high (i.e. the temperature is high or a high amount of urease), the calcite crystals will form quickly and be small in size, and thus unable to reach the neighbouring soil particles to form the strengthening bond. Conversely, if the temperature or urease amount is low, the result will consequently be slowgrowing crystals that will be too large and this will result in their pushing the soil particles apart.

This paper presents the results from a laboratory study where well-graded frictional soil has been treated using CIPS at a temperature of $10^{\circ} \mathrm{C}$ and tested by unconfined compression tests. The test samples were all prepared in a uniformly controlled manner inside a temperature-controlled room in order to mimic the average annual ground temperature in Sweden. Only one treatment was performed since the focus of this report remains on whether or not there will be a strength increase and if so, 'why', rather than on the magnitude of the increase in strength. Hence, the parameters that were tested were ground temperature $10^{\circ} \mathrm{C}$, curing time to be fully 


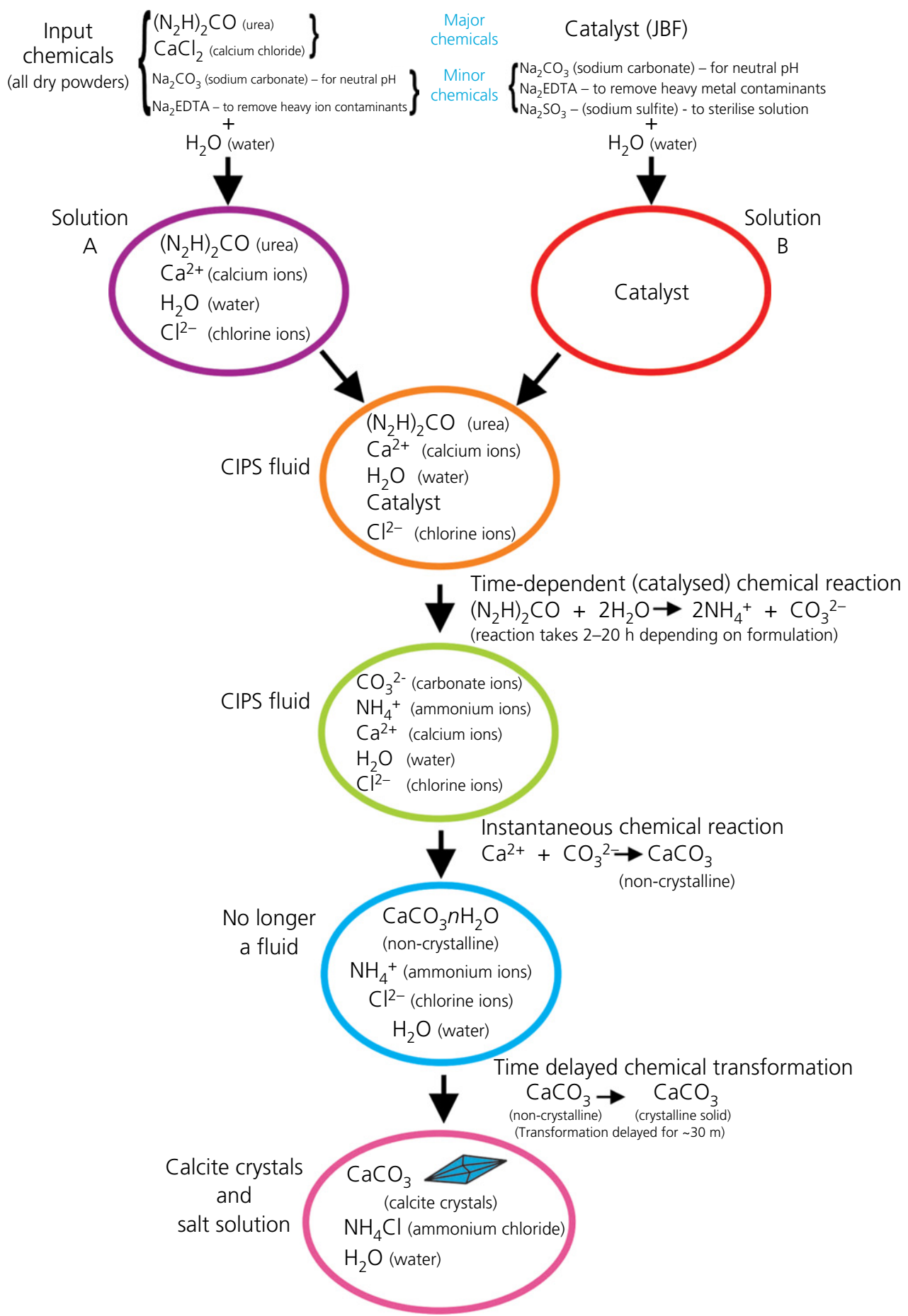

Figure 1. The chemical reaction of CIPS

saturated with CIPS at $10^{\circ} \mathrm{C}$, drying time and drying temperatures of 10 and $20^{\circ} \mathrm{C}$.

\section{Experimental procedure}

2.1 Sample preparation

Sand was gathered from a building site in the south of Stockholm. The mineral composition of this sand was established, through a petrography analysis, to $95 \%$ granite and quartz, $5 \%$ of diabase, feldspars and biotit, and had a grain distribution curve (Figure 3) ranging between 0.06 and $20 \mathrm{~mm}$. The dry density of the in situ sand was determined to be $17.77 \mathrm{kN} / \mathrm{m}^{3}$, with an initial porosity of $24.7 \%$. The petrography stated that the angularity of the grains varied from being rounded to sharp. The only adjustment that had to be made to the sand was controlling the grain size to be at 


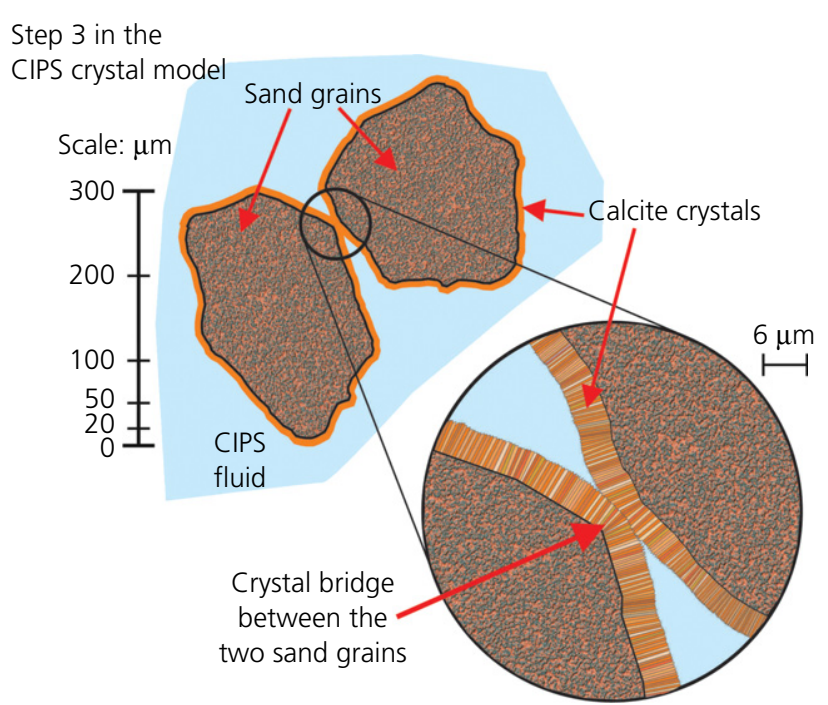

Figure 2. Display of how the coating of calcite crystals around the soil particle bond at the contact points

maximum one-tenth of the core sample diameter. The sand was passed through a $4 \mathrm{~mm}$ sieve. The compaction of the sample was conducted using a method where the calculated dry weight of sand, $0.355 \mathrm{~kg}$, was premixed in a bowl with a little extra CIPS fluid than was needed for saturating the sample fully; 0.06 litres were used in order to ensure full saturation. This mixture was thereafter stirred thoroughly for $\sim 2$ min. About $60 \mathrm{~g}$ of premixed sand and CIPS fluid were then added into a carbon fibre cylinder with diameter $50 \mathrm{~mm}$ and height $100 \mathrm{~mm}$, after which the cylinder was vibrated for about 3 min depleting all air pockets and air-filled pores. The next batch of $60 \mathrm{~g}$ CIPS saturated soil was added and the cylinder vibrated again; the same procedure was repeated until all

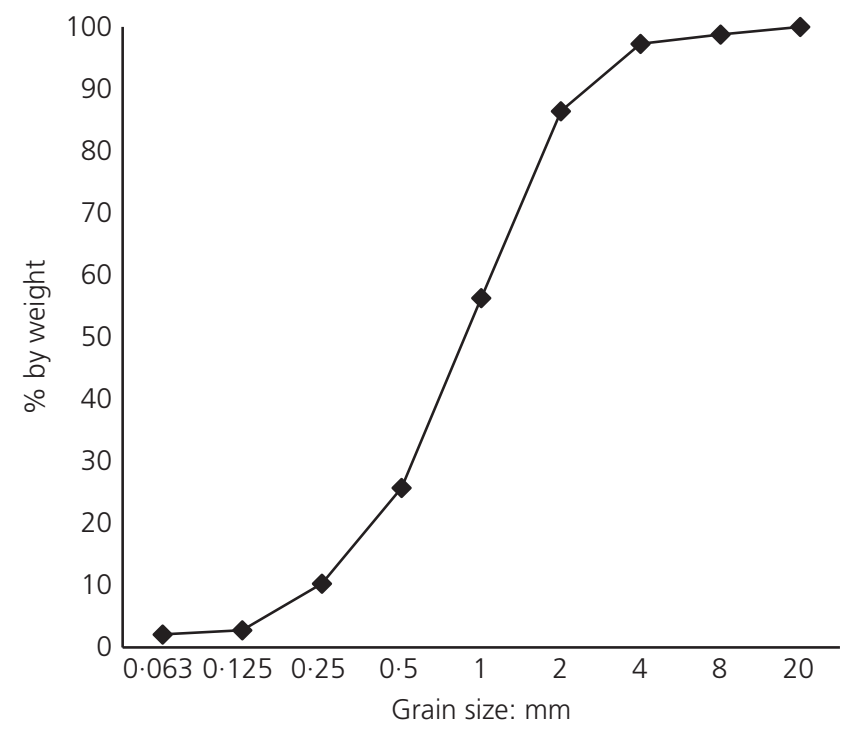

Figure 3. Grain size distribution of the tested sand of the mixture had been fitted into the cylinder and the desired density equal to the in situ density had been achieved. Sealing the cylinder with lids and tape ensured that no CIPS fluid leakage took place, nor was there any effect of drying.

Ismail et al. (2002) and Kucharski et al. (1996) both state that $5-8 \mathrm{~h}$ is enough time for most of the calcite crystals to precipitate after one CIPS treatment, resulting in the occurrence of most of the strength increase. To validate this for a ground temperature of $10^{\circ} \mathrm{C}$, the samples were left for different lengths of time in CIPS saturated conditions.

\subsection{UCS test}

The unconfined compression test was used since it is easy to conduct and is considered to be the most suited test for conducting a larger number of compression tests over a shorter period of time. The tests were performed with a deformation rate corresponding to $1 \%$ of the sample height - for example $1 \% / \mathrm{min}$. From these tests, the UCS, the strain at failure and the Young's modulus $E_{50}$ were evaluated.

The test series are displayed in Table 1 . The $x$-axis represents the time period in which the soil sample has been enclosed in the cylinder saturated with CIPS fluid. The $y$-axis represents the time period, in days, in which the samples were allowed to dry after being carefully removed from the preparation cylinder and carefully placed on a piece of paper.

\section{Result and discussion}

\subsection{Water saturated samples}

Figure 4 shows the results from UCS tests of four different tests series, each with five samples that have been left fully saturated with CIPS fluid for different periods of time at a temperature of $10^{\circ} \mathrm{C}$. There was no trend of strength increase when the samples were left for a longer cementation time. The results also show that there were only minor increases in UCS in both the CIPS saturated samples and the water saturated samples.

The lack of strength increase may be attributable to the fact that the spent fluid containing ammonium chloride has an inhibiting effect on the bridging between the grains and hence

\begin{tabular}{lcccc}
\hline & \multicolumn{4}{c}{ Time in CIPS saturated state: $d$} \\
\cline { 2 - 5 } Drying time: $d$ & 1 & 3 & 7 & 17 \\
\hline 0 & $-/ 5$ & $-/ 5$ & $-/ 5$ & $-/ 5$ \\
3 & & $5 / 5$ & & $-/ 5$ \\
14 & & $5 / 5$ & $5 / 5$ & $-/ 5$
\end{tabular}

Table 1. The test set-up showing the number of tested soil samples at each temperature 22 or $10^{\circ} \mathrm{C}$ 


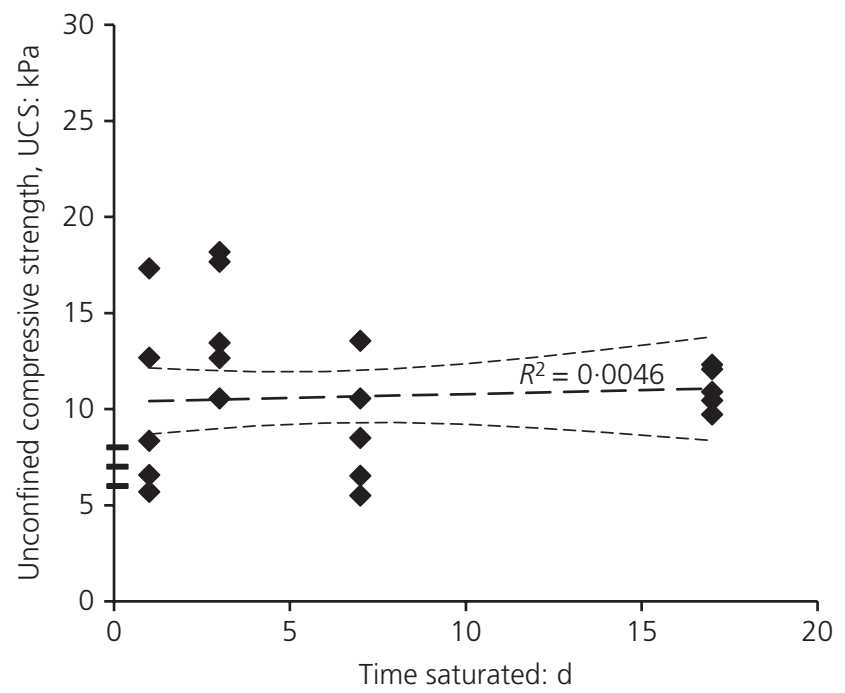

Figure 4. Relationship between UCS and number of days left in CIPS saturation. The lines to the left in the graph are sample test results based only on saturated water compacted sand

delays the strength increase from occurring in drained conditions after rinsing with water. This is an important fact which needs further to be studied in order to fully understand the influence and effect of the spent fluid.

\subsection{Dried sample}

Since there was no demonstrated strength increase caused by the cementation time, the results from exposure to air and temperature become interesting. Figure 5 presents samples which have experienced $17 \mathrm{~d}$ in CIPS saturated condition and thereafter, left to dry for 0,3 and $14 \mathrm{~d}$ before being tested. The coefficient of determination $R^{2}=0.72$ indicates a good correlation between the increase in UCS with time exposed to air. Figure 6 displays samples that have experienced $3 \mathrm{~d}$ in CIPS saturated condition and thereafter, left to dry for 0,3 and $14 \mathrm{~d}$ at 10 and $20^{\circ} \mathrm{C}$ before being tested. The results indicate a strong correlation between UCS and drying time with coefficients of determination $R^{2}=0 \cdot 80$ and $R^{2}=0 \cdot 96$, respectively.

The difference of $14 \mathrm{~d}$ in CIPS saturated conditions between the samples in Figures 5 and 6 supports the results in Figure 4, where the lack of relationship between UCS increases with longer saturation time is indicated. Ismail et al. (2002) also demonstrated that as almost all of the calcite had precipitated $5 \mathrm{~h}$ after treatment, most of the strength increase had developed. Further, the results indicate that the difference in temperature at which the samples were air dried does not have a significant effect on the strength increase.

Figure 7 further illustrates that the curing time had no significant effect on the strength increase. The different sample series in this graph were all exposed to air for $14 \mathrm{~d}$ but at two

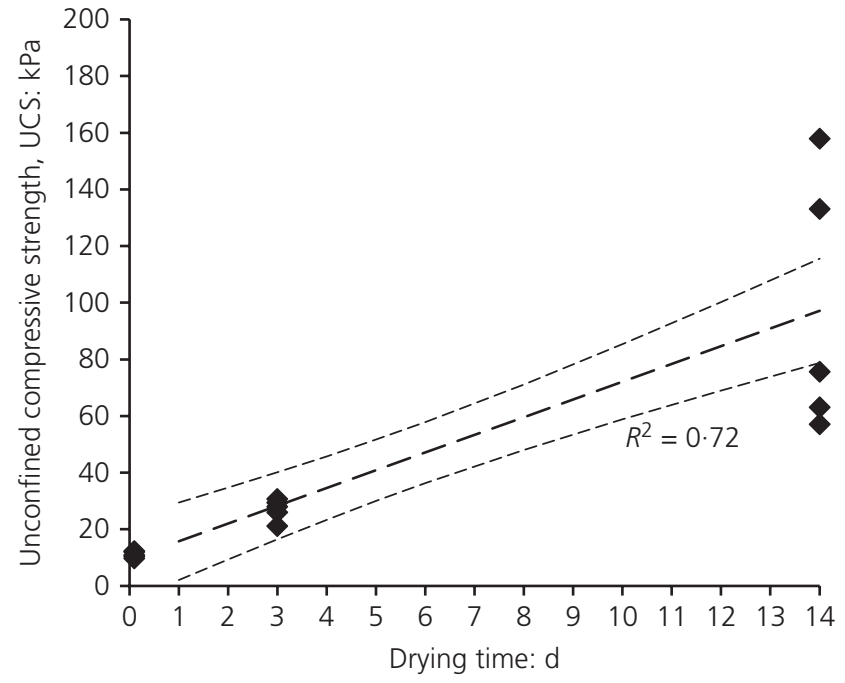

Figure 5. Relationship between UCS and number of days left for drying at $10^{\circ} \mathrm{C}$. All test samples have been left in CIPS saturation for $17 \mathrm{~d}$ at $10^{\circ} \mathrm{C}$, before exposure to air and temperature of $10^{\circ} \mathrm{C}$

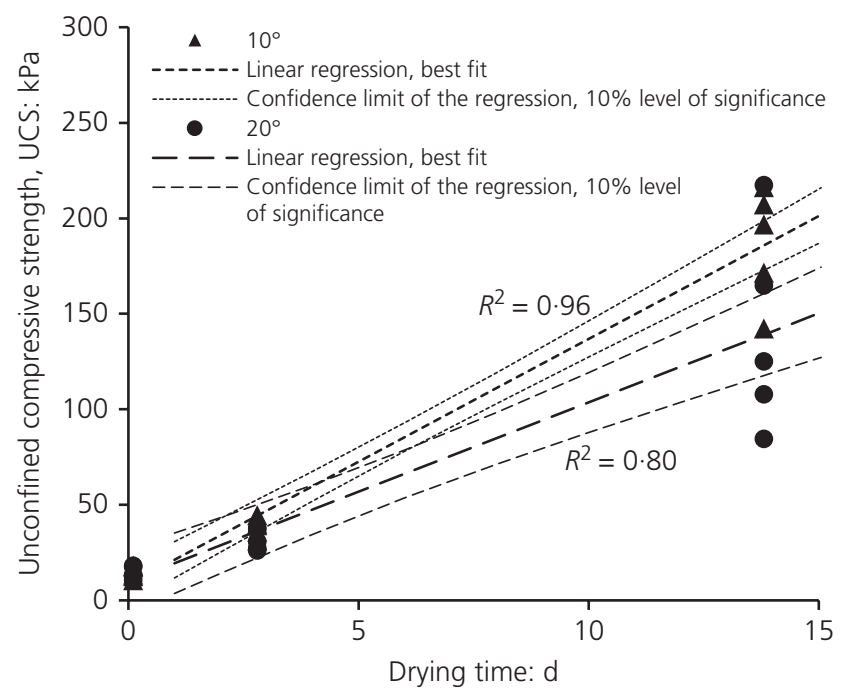

Figure 6. Relationship between UCS and number of days left for drying at $10^{\circ} \mathrm{C}(\bullet)$ and $20^{\circ} \mathrm{C}(\bullet)$. All tests have been left in CIPS saturation for $3 \mathrm{~d}$ at $10^{\circ} \mathrm{C}$, before exposure to air and drying

different temperatures -10 and $20^{\circ} \mathrm{C}$; the difference between the sample series is the cementation time before exposure to air.

Nearly all samples demonstrated an almost ten-fold increase in strength due to the $14 \mathrm{~d}$ air exposure compared with the samples tested under saturated conditions (Figure 4), but there is no indication that longer cementation time would have any effect on strength increase. The four plotted results below the $50 \mathrm{kPa}$ at $7 \mathrm{~d}$ in Figure 7 (resembling two dots) appeared 


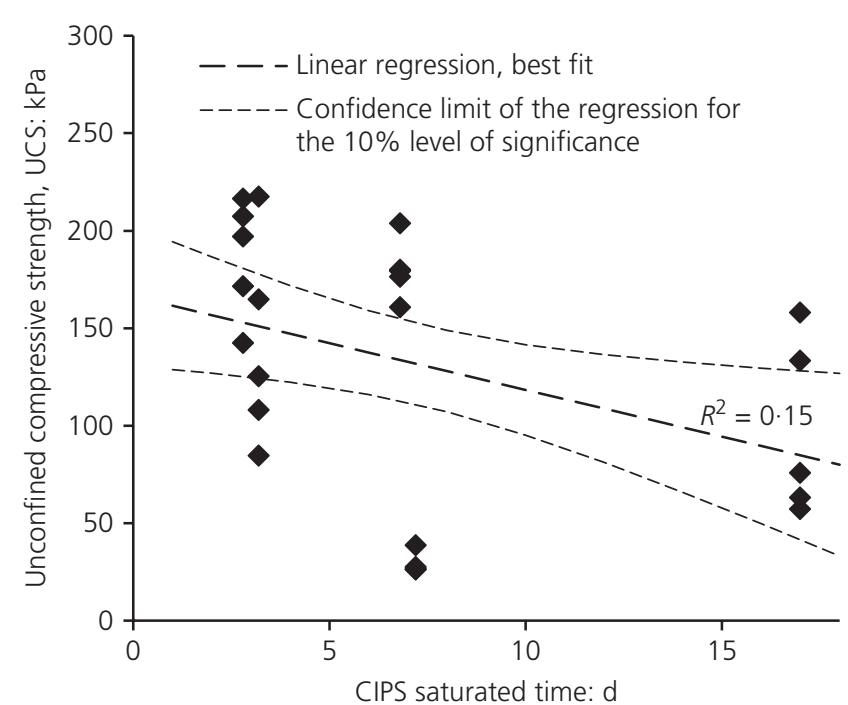

Figure 7. Relationship between UCS and different number of days left in CIPS saturation. All samples have been left to dry for $14 \mathrm{~d}$ but at different temperatures, $10^{\circ} \mathrm{C}(\bullet)$ and $20^{\circ} \mathrm{C}(\bullet)$. The samples located below $50 \mathrm{kPa}$ at $7 \mathrm{~d}$ might have been subjected to an external factor causing them to fail. These samples were experienced as wet during testing

somewhat moist during the compression tests and indicate something might have gone wrong during the preparation. Neglecting these four samples will result in a coefficient of determination closer to zero, stating the already established result, from Figure 4, of no correlation between time in CIPS saturated condition and strength increase.

One treatment with CIPS fluid and $14 \mathrm{~d}$ of drying resulted in an UCS of $100-200 \mathrm{kPa}$ compared with $\sim 400 \mathrm{kPa}$ that was achieved by Ismail et al. (2002). Although the level of UCS increase in this study only reached approximately half the UCS increase achieved by Ismail et al. (2002), these tests still resulted in a soil strength increase in Scandinavia's colder climate when done in combination with more well-graded sandy material. The difference in UCS can be caused by many factors such as different mineral composition and grain size distribution. Plotting $E_{50}$ against the UCS, in Figure 8, illustrates a strong relationship that is approximately $E_{50}=1150 \times$ UCS with a coefficient of determination $R^{2}=0 \cdot 96$. The test samples that were all left to dry for $14 \mathrm{~d}$, disregarding the different number of days these were saturated with CIPS fluid, displayed an evaluated $E_{50}$ ranging between $29 \cdot 8$ and $277.8 \mathrm{MPa}$. This is after just one treatment with the chosen CIPS formulation that can precipitate an estimated maximum of $6.05 \mathrm{~g}$ of calcite for the pore volume of the test sample. These are rather high values of $E_{50}$ for such a small amount of precipitated calcite as compared with the results of Yasuhara et al. (2012) and Van Paassen (2009). The deformation at maximum compressive strength for these results is plotted in

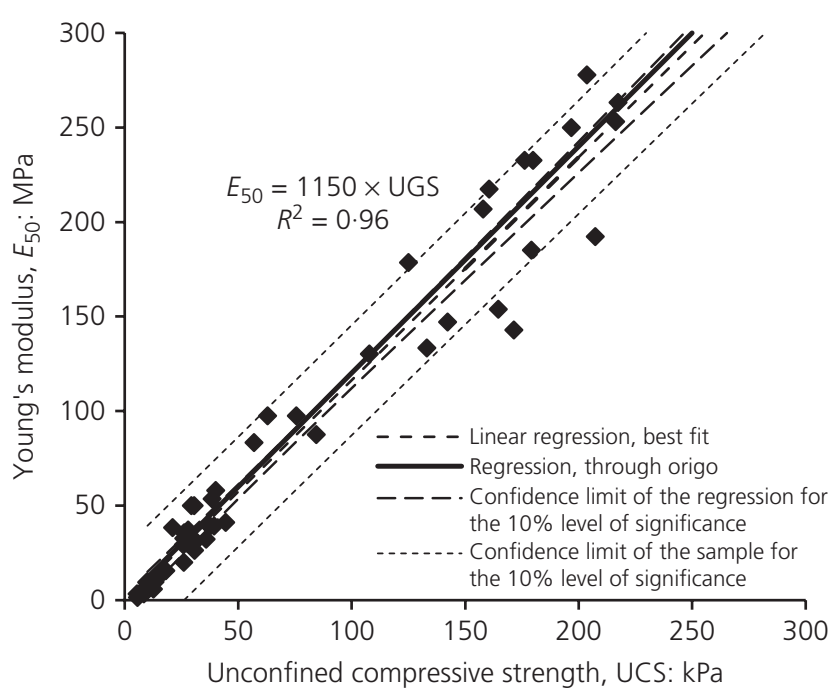

Figure 8. Relationship between Young's modulus, $E_{50}$ and UCS

Figure 9. Circles $(\bullet)$ are samples which have been tested in CIPS saturated condition and the diamonds ( $\bullet$ ) are the dried samples. This plot demonstrates a strain - ranging from 0.7 to $2 \cdot 6 \%$ - for both CIPS saturated samples and samples exposed to air. The air exposed samples exclusively range from 0.7 to $1.9 \%$. The strain results obtained in this study correspond fairly well to the normal strain results obtained by Yasuhara et al. (2012), ranging between 0.48 and $0.92 \%$.

\section{Conclusions}

In this study, a series of test samples have been created using the permeation grouting method CIPS and tested for UCS. The evaluation of unconfined strength increase was carried out on test samples created at $10^{\circ} \mathrm{C}$ and air dried at around 10 and $20^{\circ} \mathrm{C}$.

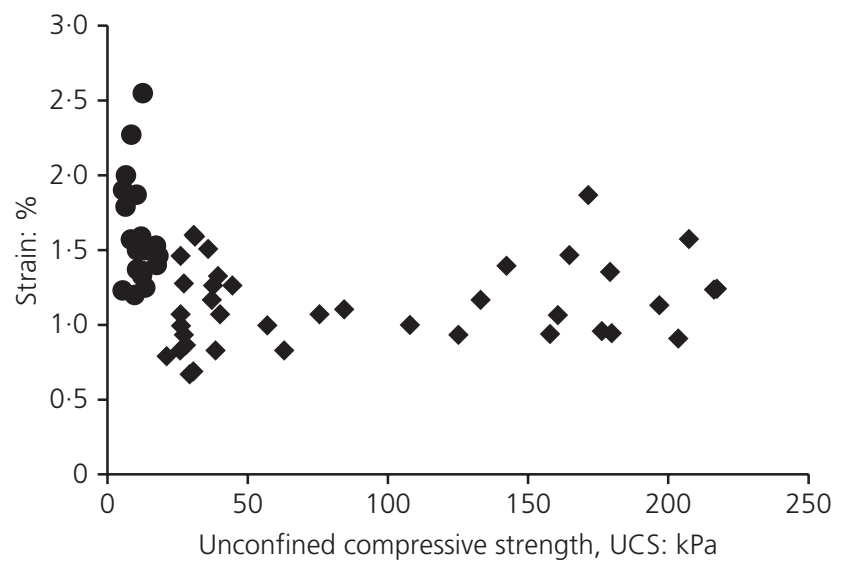

Figure 9. Relationship between strain and UCS. Samples tested in CIPS saturated condition are indicated with $(\bullet)$ and samples exposed to air and temperature are represented with $(\bullet)$ 
CIPS produced similar results of strength increase at $10^{\circ} \mathrm{C}$ as for $>20^{\circ} \mathrm{C}$, which leads to the conclusion that the method is useful in climates that have an average ground temperature of at least $10^{\circ} \mathrm{C}$, as well as in warmer climates.

An extended time of drying resulted in a higher UCS increase; this UCS increase ranged between 85 and $217 \mathrm{kPa}$ for samples which were all left for $3 \mathrm{~d}$ in CIPS saturated condition and thereafter, opened up to dry for $14 \mathrm{~d}$ at 10 and $20^{\circ} \mathrm{C}$. Accordingly, the increase in $E_{50}$ modulus ranged between 30 and $279 \mathrm{MPa}$, with a very strong relationship between $E_{50}$ and USC.

\section{Acknowledgement}

The authors acknowledge the support of the Development Fund of the Swedish Construction Industry.

\section{REFERENCES}

Ismail M, Joer H and Randolph MF (2000) Sample preparation technique for artificially cemented soils. Geotechnical Testing Journal 23(2): 171-177.

Ismail M, Joer H, Randolph MF and Meritt A (2002)

Cementation of porous materials using calcite. Géotechnique 52(5): 313-324, http://dx.doi.org/10.1680/ geot.52.5.313.38709.

Kucharski E, Price G, Li H and Joer HA (1996) Laboratory evaluation of CIPS cemented calcareous and silica sands. In Proceedings of 7th Australia New Zealand
Conference on Geomechanics (Jaska MB, Kaggwa WS and Cameron DA (eds)). ACT, Barton, Australia, pp. 102-107.

Kucharski E, Chow F, Price G, Vaughan P and McGinnity B (2000) Investigations into the stabilisation of ash using the calcite in situ precipitation system. In Proceedings of GeoEng 2000, Melbourne, Australia. Technomic Publishing Company, Lancaster, PA, USA (CD-ROM).

Price G (1988a) The potential benefits of fabric studies on calcareous sediments. In Proceedings of International Conference on Calcareous Sediments (Jewell RJ and Andrews DC (eds)). Balkema, Rotterdam, the Netherlands, vol. 2, p. 881 .

Price G (1988b) Fabric of calcareous sediments at North Rankin 'A,' North West Shelf. In Proceedings of International Conference on Calcareous Sediments (Jewell RJ and Andrews DC (eds)). Balkema, Rotterdam, the Netherlands, vol. 2, pp. 367-376.

Tatzki T (2003) CIPS - A New Permeation Grouting System. Carbo Tech Fosroc GmbH, Essen, Germany.

Van Paassen LA (2009) Biogrout: Ground Improvement by Microbially Induced Carbonate Precipitation. PhD dissertation, Delft University of Technology, Delft, the Netherlands.

Vaughan PR, Kucharski ES, Chow FC et al. (2001) Experimental Treatment of an Old Track-Bed Using CIPS. London Underground Ltd and Infraco JNP Ltd, London, UK. Yasuhara H, Neupane D, Hayashi K and Okamura M (2012) Experiments and predictions of physical properties of sand cemented by enzymatically-induced carbonate precipitation. Soil and Foundations 52(3): 539-549.

\section{WHAT DO YOU THINK?}

To discuss this paper, please email up to 500 words to the editor at journals@ice.org.uk. Your contribution will be forwarded to the author(s) for a reply and, if considered appropriate by the editorial panel, will be published as discussion in a future issue of the journal.

Proceedings journals rely entirely on contributions sent in by civil engineering professionals, academics and students. Papers should be 2000-5000 words long (briefing papers should be 1000-2000 words long), with adequate illustrations and references. You can submit your paper online via www.icevirtuallibrary.com/content/journals, where you will also find detailed author guidelines. 